Article

\title{
Study of the Stiffness Characteristics of Waist Type Laminated Membrane Coupling Considering Flange Elasticity
}

\author{
Miaomiao Li ${ }^{1} * \mathbb{C}$, Yinghao Zhao ${ }^{1}$, Rupeng $\mathrm{Zhu}^{1}$ and Pingjun $\mathrm{Li}^{2}$ \\ 1 National Key Laboratory of Science and Technology on Helicopter Transmission, Nanjing University of \\ Aeronautics and Astronautics, Nanjing 210016, China; yinghaozhao1993@163.com (Y.Z.); \\ rpzhu@nuaa.edu.cn (R.Z.) \\ 2 AECC Hunan Aviation Powerplant Research Institute, Zhuzhou 412000, China; research1986@163.com \\ * Correspondence: limiaomiao@nuaa.edu.cn; Tel.: +86-15905168902
}

Received: 3 September 2020; Accepted: 12 October 2020; Published: 14 October 2020

check for updates

\begin{abstract}
Studies show that the systematic study of the stiffness characteristics of the laminated membrane coupling is helpful to analyze the vibration status of the shaft system deeply and accurately. Moreover, such an investigation can provide a reliable guarantee for the safe operation of the power plant. Therefore, establishing an accurate expression for the stiffness and analyzing its characteristics have great significance. In the present study, a finite element model of the waist type laminated membrane coupling is established which considers the influence of the contact between laminations. In order to evaluate the performance of the proposed method, four stiffness characteristics of the coupling are analyzed, including torsional, axial, radial and angular stiffness. The torsional stiffness is verified by the static torsional test. The influence of the flange elasticity and the friction coefficient between the laminations on the stiffness characteristics of the coupling is studied. In the present study, variations of the flange stiffness, the pre-tightening force of the bolt and the friction coefficient between the laminations are studied based on the results obtained from the finite element method. It is expected that the present study can provide a reference for designing and application of the lamination coupling.
\end{abstract}

Keywords: laminated membrane coupling; flange elasticity; stiffness characteristics; friction between laminations

\section{Introduction}

Laminated membrane coupling is an all-metal dry flexible coupling, which can compensate relative displacements between the driving and driven shafts through the elastic deformation of the laminated group. Superior characteristics of these couplings, including the compact structure, reliable connection, simple maintenance and excellent environmental adaptability, have led to the widespread use of these components in diverse industrial applications such as petroleum and chemical industry, aviation, ships and wind turbines [1,2].

Different types of laminated membrane couplings have been proposed so far. These couplings can be divided into the ring type, spoke type, multilateral type, connecting rod type and the waist type. Among these types, the waist type lamination can achieve the optimal stress distribution on the premise of the least material without a remarkable impact on its performance [3]. Studies show that the waist type lamination has reasonable elasticity. However, the manufacturing process of this type of coupling is relatively complicated.

Laminated membrane coupling plays a key role in mechanical power transmission. Its working reliability is directly related to the safety of the power transmission device and even the whole 
system. On the other hand, the stiffness of the laminated membrane coupling reflects its ability to compensate misalignment displacements, which is the basic index that must be considered for evaluating the coupling characteristics. Accordingly, the systematic study of the stiffness characteristics of the laminated membrane coupling is of significant importance to analyze the shaft vibration deeply and accurately. Then a reliable guarantee can be provided for the safe operation of the power plant.

Reviewing the literature indicates that many scholars have carried out investigations on laminated membrane coupling. Kilaekim studied the correlation between the low cycle fatigue properties and the adhesive properties of laminations [4]. Shen Tuliufang studied the stress of laminated membrane coupling subjected to diverse torques and axial loads, and emphatically compared the influence of different transmitted powers and axial displacements on the laminated stress [5]. Furthermore, Shentu Liufang et al. applied MATLAB software to optimize laminated parameters of the coupling [6]. Caliciotti proposed a heuristic adaptive truncation criterion based on linear search and internal iteration of truncated Newton method. The effectiveness and robustness of the adaptive criterion were verified by numerical experience of unconstrained optimization problems, which has important reference significance for optimization problems [7,8]. Kazerounian and Duong performed a finite element analysis and found that the structural performance of the flexible tapered diaphragm coupling, which is applied in the aerospace industry, is mainly related to the outer diameter of lamination and the stress intensity at the joint of the rim support structure. Then they designed an asymmetric tapered diaphragm structure [9]. Khosravi carried out an efficient and accurate nonlinear finite element analysis and proposed an optimization design method for thin-walled structures. He modified the composite laminated plate element to consider the bending coupling effect of the diaphragm [10]. Ganesan et al. proposed an effective surface shell element to analyze the geometric nonlinearity of composite laminated structures by the common rotational method, and then analyzed some laminated composite structures with nonlinear geometries [11]. Khosravi et al. proposed an effective surface shell element to analyze the geometric nonlinearity of laminated structures with materials by the common rotation method. They showed that the proposed method can be applied to analyze the limit load of laminated structures [12]. Moreover, Cheng Ming studied the stress characteristics of the square laminated membrane coupling and then analyzed the influence of the guard plate on the laminated stress [13]. Zhong Kai et al. conducted a detailed analysis on the membrane stress of the high-power laminated membrane coupling, pointed out the stress distribution characteristics of the elastic element and calculated its torsional stiffness [14]. Shen Tuliufang proposed a four-hole joint bearing coupling structure to improve the angular displacement compensation ability of the laminated membrane coupling between two shafts. Then they analyzed the maximum stress position and non-centering compensation ability of three different coupling sizes through mechanical experiments and finite element simulation methods [15]. Deng Guanglin et al. studied the strength and stiffness of the diaphragm assembly in direct contact with plates in the diaphragm assembly, and analyzed the influence of the number of layers of the diaphragm assembly and the preload value of the diaphragm assembly gasket on the strength and stiffness of the diaphragm assembly [16]. Wang Wei applied the finite element method and established a model for the multi-layer contact coupling. He demonstrated that results obtained from the stress calculation can more accurately show the stress characteristics of elastic elements when the comparison is made with the conventional single-chip model [17]. Sun Chenglong et al. established the stiffness model for the diaphragm of the joint type laminated membrane coupling based on the relevant mathematical expressions and classical mechanics. They showed that the compensation ability of the joint laminated membrane coupling for radial and angular displacements is far better than that of the ordinary laminated membrane coupling [18,19]. Nie Junfeng proposed a mathematical model for the contact stiffness of the lamination group and showed the accuracy and superiority of the lamination group for calculating the stiffness of the lamination coupling [20]. Recently, Liu Jingming applied the finite element simulation method to analyze the correlation between structural parameters and the torsional stiffness of the laminated membrane coupling, and found that the laminated thickness, the diameter and total number of bolts 
have a certain impact on the torsional stiffness of the coupling [21]. More recently, Liang Youtao et al. analyzed the influence of the bolt-predicted force and the friction coefficient on the stress and stiffness of laminated membrane coupling. They utilized the finite element method and studied the correlation between the misalignment slip and nonlinear characteristics of the coupling [22].

Reviewing the literature indicates that in the majority of performed numerical simulations for investigating laminated membrane couplings, the surface shear and extrusion caused by small relative motions between laminations are ignored. Moreover, it is assumed that the external load is evenly distributed in each lamination. Based on these assumptions, only the single lamination was analyzed. However, the contact stiffness is produced in laminated contact. This is especially more pronounced for extreme deformations and heavy loads. In these cases, the shear, radial and torsional stresses and angular deformations caused by the contact cannot be ignored. In real applications, the internal contact between laminations and the contact between laminations and the gasket affect the lamination state. Therefore, calculate the overall stiffness of the lamination coupling, which is not in line with the actual working condition. In other words, it is necessary to consider the elastic deformation and the contact deformation of the lamination surface, and study the lamination coupling as a whole.

In the present study, it is intended to establish a finite element model of the waist type laminated membrane coupling. To this end, contacts between 16 pieces of laminations are considered. Moreover, an appropriate mesh is utilized and boundary conditions are set. Four stiffness characteristics of the coupling, including the torsional, axial, radial and angular stiffness are analyzed, and the torsional stiffness is verified through the static torsional test. In order to investigate the influence of the flange elasticity and the friction between laminations on the stiffness characteristics of the coupling, different flange stiffness, pre-tightening bolt forces and friction coefficients are considered in simulations. It is expected that the present study can provide a reference for designing the lamination coupling.

\section{Stiffness Simulation Verification of the Waist Type Laminated Membrane Coupling Considering Flange Elasticity}

\subsection{The Waist Type Laminated Membrane Coupling}

Figure 1 illustrates the configuration of the six-hole waist type laminated membrane coupling. It is observed that the coupling consists of an active flange, bolt connection component and metal laminated group. Moreover, the working principle of this type of coupling can be described as the following: The torque is input from the flange at the drive end, and then transmitted to the metal laminate group by means of precision bolts through reaming holes at circular cross intervals. The output torque of the flange is then applied to the driven end by adjacent precision bolts.

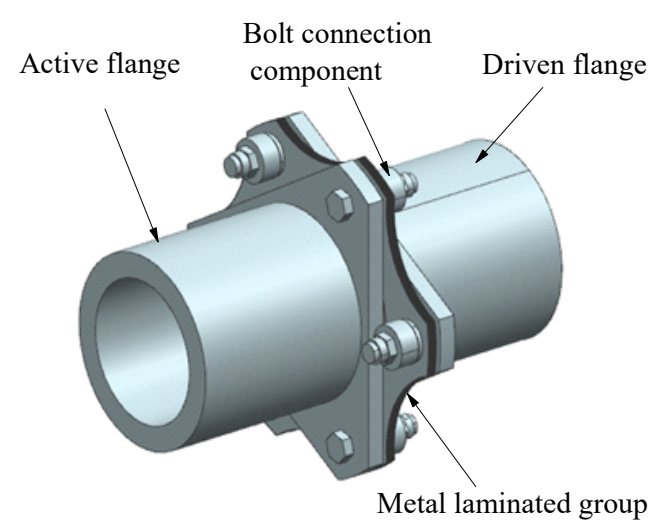

Figure 1. Configuration of the waist type laminated membrane coupling.

Figure 1 indicates that the assembly of the lamination coupling is composed of 16 pieces of hexagonal stainless steel rings with the same thickness. It should be indicated that the thickness of each piece is $0.4 \mathrm{~mm}$. Figure 2 shows that these rings are assembled to the flange plate through bolts, 
flange bushing, spherical washer, bushing and self-locking nut. Moreover, Figure 3 illustrates the lamination group used in this study.

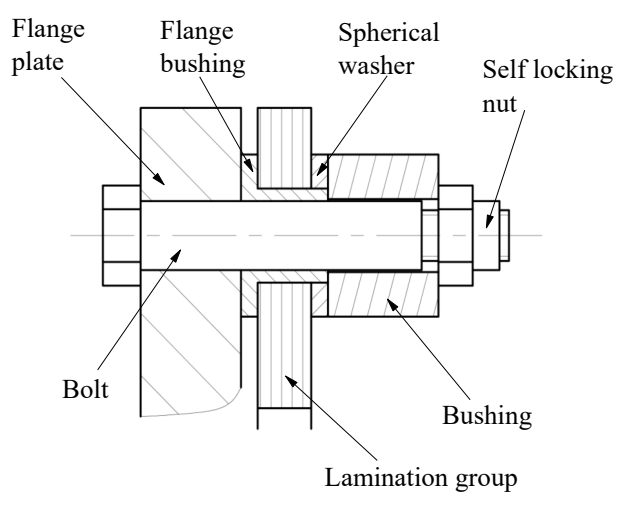

Figure 2. Partial assembly of the lamination group.

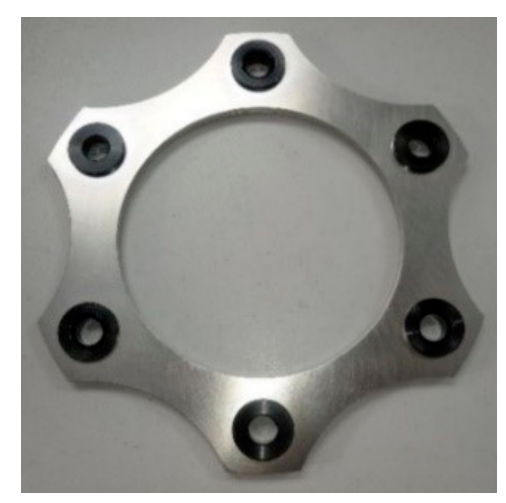

Figure 3. Assembly of the waist type lamination.

Figure 4 shows the principle of the lamination group. Assuming that bolt holes 1, 3, and 5 (shown in shade) are connected to the side of the driving shaft, bolt holes 2, 4, and 6 (shown in hollow) are connected to the side of the driven shaft, and the driving shaft rotates clockwise. Based on the above, the arc segments on the laminated sheet are divided into two statuses: the interval is compressed and stretched. The torque transmission is mainly based on the stretch arc. This structure can optimize the force distribution in the lamination when the torque is loaded. The main geometric parameter identification diagram of the lamination is shown in Figure 5, and the values of each geometric parameter are shown in Table 1.

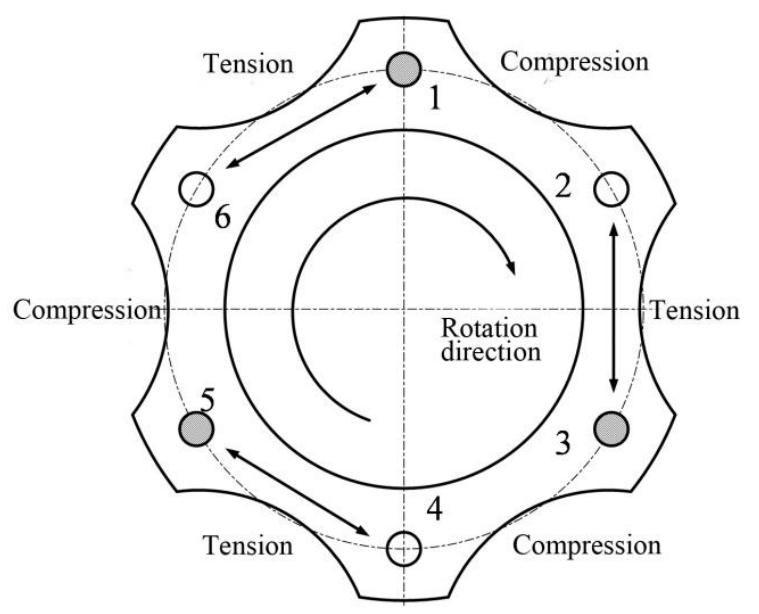

Figure 4. Principle of lamination transfer torque. 


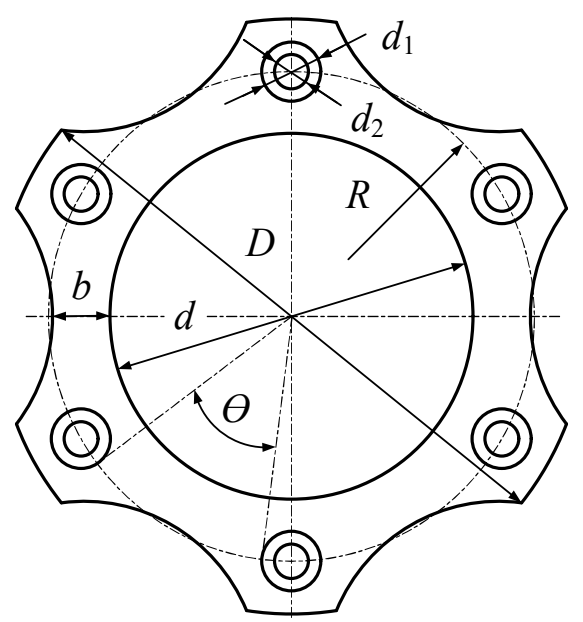

Figure 5. Main geometric parameters of laminations.

Table 1. Parameters of laminations (mm).

\begin{tabular}{ccccccc}
\hline $\begin{array}{c}\text { Outer Diameter } \\
\text { of Lamination }(\boldsymbol{D})\end{array}$ & $\begin{array}{c}\text { Inner Diameter } \\
\text { of Lamination }(\boldsymbol{d})\end{array}$ & $\begin{array}{c}\text { Inner Diameter } \\
\text { of Spherical } \\
\text { Washer }\left(\boldsymbol{d}_{\mathbf{2}}\right)\end{array}$ & $\begin{array}{c}\text { Outer Diameter } \\
\text { of Spherical } \\
\text { Washer }\left(\boldsymbol{d}_{\mathbf{1}}\right)\end{array}$ & $\begin{array}{c}\text { Center Circle } \\
\text { Radius of Bolt } \\
\text { Hole }(\boldsymbol{R})\end{array}$ & $\begin{array}{c}\text { Radial } \\
\text { Minimum } \\
\text { Width }(\boldsymbol{b})\end{array}$ & $\begin{array}{c}\text { Single } \\
\text { Laminated } \\
\text { Thickness }(\boldsymbol{t})\end{array}$ \\
\hline 226 & 139 & 13 & 28 & 93 & 22 & 0.4 \\
\hline
\end{tabular}

Due to various errors between the driving and driven shafts, the laminated coupling bears the stresses caused by axial, radial and angular displacements under un-working conditions. The laminated coupling will be affected by torque and centrifugal force in working state, and its stress state is very complex. In order to ensure the maximum stress under each load does not exceed the strength limit of the laminate itself, the effects of each load need to be calculated separately.

\subsection{Simulation of Torsional Stiffness of the Waist Type Laminated Membrane Coupling}

In fact, in a considerable number of work conditions, the friction caused by the contact between the laminations cannot be ignored. In the working process, the state of the coupling will be affected by the contact between the laminations and between the laminations and the gaskets. The characteristics of the coupling are the comprehensive performance of the interaction between the laminations and the laminations, as well as between the laminations and their connectors. Therefore, it is ideal and rough to calculate the stress level of the laminated coupling simply by analyzing a single laminated plate. Therefore, it is necessary to consider the contact and friction between the laminated plates and analyze the laminated coupling as a whole.

The three-dimensional model of the coupling is established by CATIA software. The established 3D model is imported into the finite element software workbench and material properties are defined in the software according to the data provided in Table 2.

Table 2. Quantity, material and mechanical characteristics of main parts in the assembly.

\begin{tabular}{|c|c|c|c|c|c|}
\hline Part & Quantity & Material & $\begin{array}{c}\text { Density } \\
\rho\left(\mathrm{kg} / \mathrm{m}^{3}\right)\end{array}$ & $\begin{array}{c}\text { Elastic } \\
\text { Modulus } E(\mathbf{P a})\end{array}$ & Poisson Ratio $\mu$ \\
\hline Flange plate & 2 & 30CrNi4MoA & 7885 & $2.04 \times 10^{11}$ & 0.307 \\
\hline Spherical washer & 6 & 30CrMnSiA & 7750 & $1.96 \times 10^{11}$ & 0.3 \\
\hline Flange bushing & 6 & 30CrMnSiA & 7750 & $1.96 \times 10^{11}$ & 0.3 \\
\hline Bushing & 6 & 30CrMnSiA & 7750 & $1.96 \times 10^{11}$ & 0.3 \\
\hline Bolt & 6 & 30Ni4CrMoA & 7849 & $2.04 \times 10^{11}$ & 0.308 \\
\hline Self-locking nut & 6 & $30 \mathrm{CrMoA}$ & 7820 & $2.09 \times 10^{11}$ & 0.279 \\
\hline Lamination & 16 & 301 stainless steel & 7930 & $2.12 \times 10^{11}$ & 0.3 \\
\hline
\end{tabular}


The workbench simulation software is used for the simulation of the waist type laminated membrane coupling, and the multi-zone method is used to automatically divide the grid. By setting the element size, the density of the divided grid is adjusted. In the calculation, the grid size of the laminated sheet is set to $2 \mathrm{~mm}$, the grid size of bolts, nuts, bushings, etc. is $4 \mathrm{~mm}$, and the grid size of the two flanges is $8 \mathrm{~mm}$. The number of component mesh nodes is 536,163 and the number of cells is 74,045. The final meshing effect is shown in Figure 6.

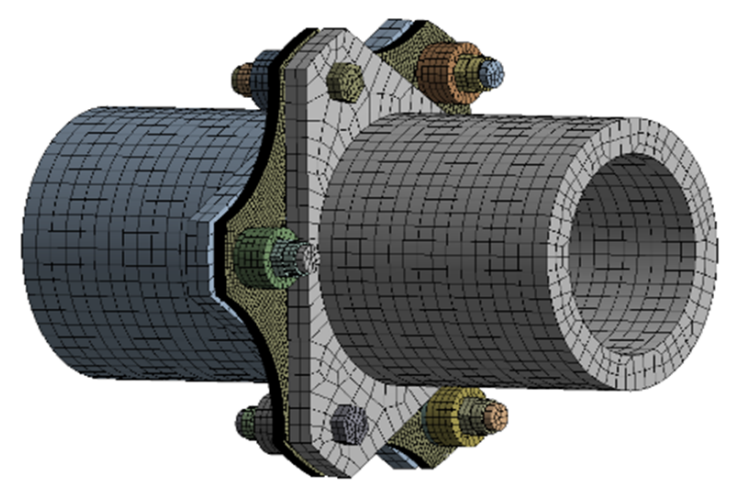

Figure 6. Generated mesh for the waist type laminated membrane coupling.

It is worth noting that contacts between bolts and nuts, flange plates, lamination and flange bushing and washers are set as bonded, while contacts between the bushing and bolt, nut and washer are as no-separation. Meanwhile, contacts between laminations are set as frictional contact. It means that there is separation in normal direction and relative sliding along the tangent direction. According to the material and surface roughness of coupling, the friction coefficient between the laminations is set to 0.2 .

As shown in Figure 7, according to the relevant parameters provided by the coupling manufacturer, the pre-tightening force of the connecting bolts between driving and driven flanges are set to $15 \mathrm{kN}$, the preload is applied to each bolt. After fixing the driven flange, a torque of $3000 \mathrm{~N} \cdot \mathrm{m}$ is applied on the active flange, and then the torsional stiffness of the laminated membrane coupling is simulated.

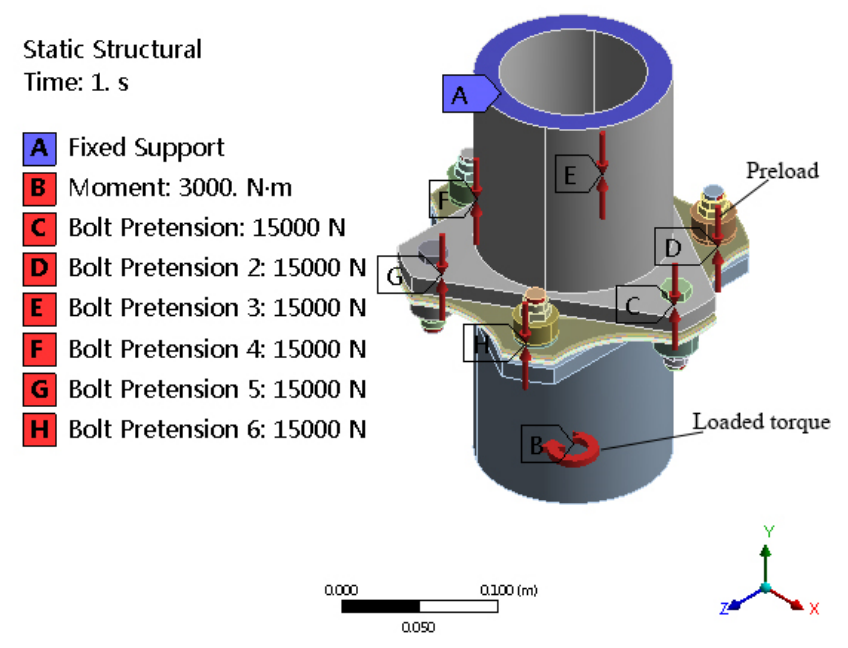

Figure 7. Boundary condition setting under torque.

After calculation by finite element software, the deformation diagram of the outermost layer of the coupling model under the action of torque is obtained, as shown in Figure 8. In order to obtain an accurate deformation torsion angle $\varphi$, a remote point is set on the cylindrical end face of the flange, and then a flexible rotation probe is added here, as shown in Figure 9. 


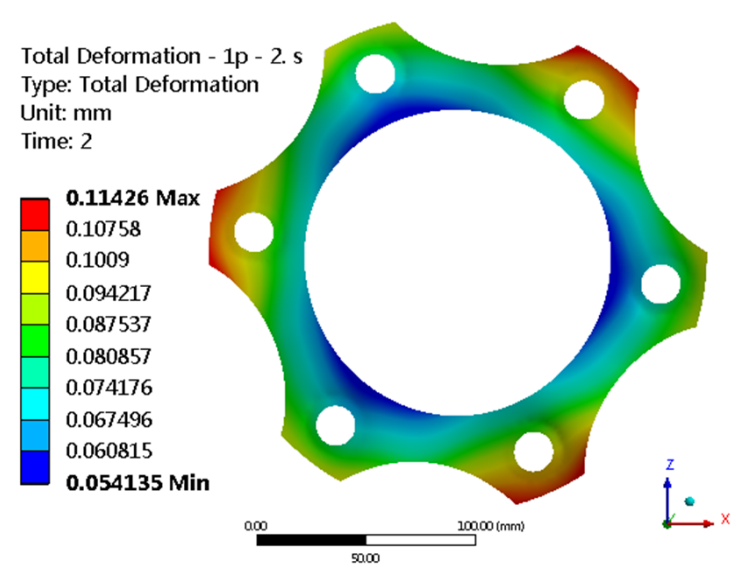

Figure 8. Deformation of the lamination under the action of torque.

Flexible Rotation Probe

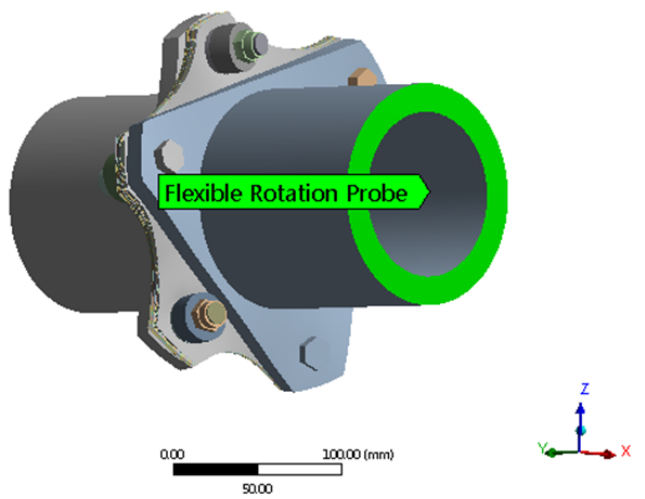

Figure 9. Adding a flexible rotation probe.

Mathematical expression for calculating the torsional stiffness $K_{T}$ of the laminated membrane coupling can be rewritten in the form below:

$$
K_{T}=\frac{\mathrm{d} T}{\mathrm{~d} \varphi} \approx \frac{\Delta T}{\Delta \varphi}
$$

Obtained torsional stiffness of the laminated membrane coupling is $1.79 \times 10^{6} \mathrm{~N} \cdot \mathrm{m} / \mathrm{rad}$.

\subsection{Test and Verification of the Torsional Stiffness of the Waist Type Laminated Membrane Coupling}

In order to evaluate the simulation accuracy, the static torsional experiment is carried out to measure the torsional stiffness of the laminated membrane coupling. To this end, a PNW-5 electro-hydraulic servo shaft torsional fatigue test machine (Science and Technology Company, Shandong, China) is employed. Figure 10 shows that the test machine is mainly composed of a pump station, test bench and a computer with WinQuick software. This testing machine is applied to carry out the load test on the laminated membrane coupling. Then the simulation results of the torsional stiffness of the coupling are verified.

In order to perform the test, it is necessary to find out the zero point position of the hydraulic cylinder and the installation position of the test piece. To this end, the coupling should be installed in the shaft center. Figure 11 shows that the coupling is connected to the left and right connecting plates through the left and right connecting shafts, respectively.

During the experiment, the applied torque is gently applied from the connecting disk at one end to $3000 \mathrm{~N} \cdot \mathrm{m}$. Simultaneously, the corresponding angular displacement and torque of the connecting 
disk are recorded through the sensor. Figure 12 illustrates the distribution of the torque $T$ against the angular displacement $\varphi$.

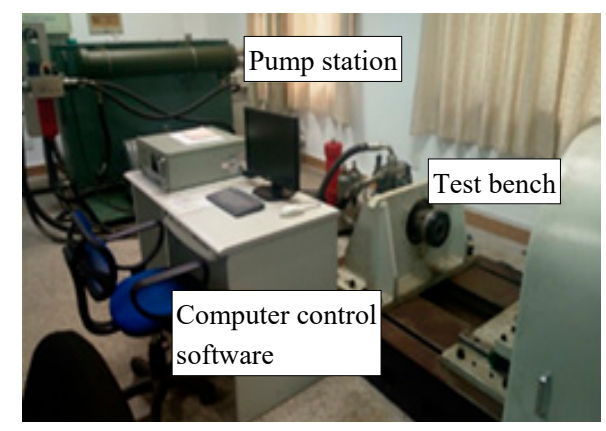

Figure 10. Configuration of the torsional fatigue testing machine.

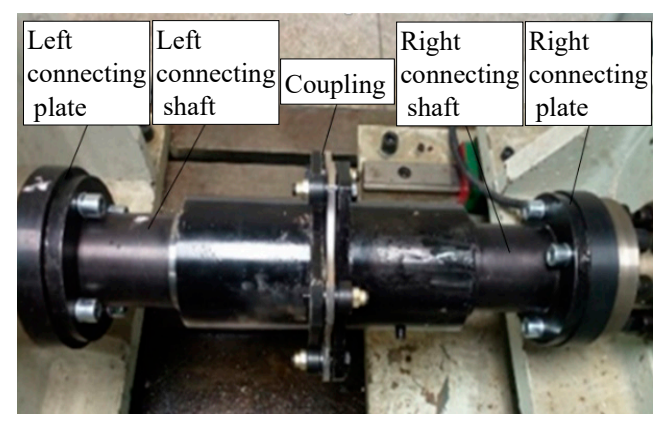

Figure 11. Installation drawing of the coupling.

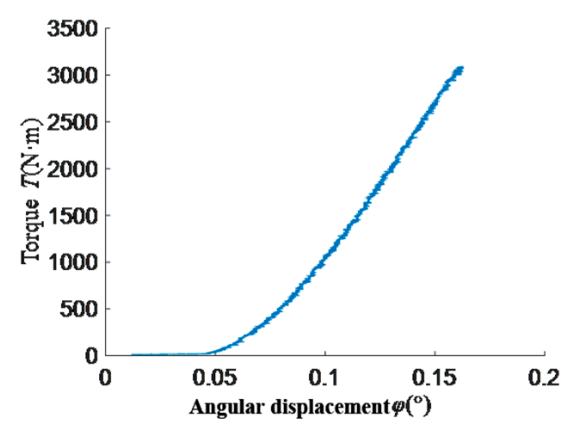

Figure 12. Distribution of torque $T$ applied on the laminated membrane coupling against the angular displacement $\varphi$.

The horizontal line before $0.05^{\circ}$ indicates that the angular displacement $\varphi$ increases, while the torque $T$ remains zero. This originates from the gap along the circumference of the test piece. Moreover, when the angular displacement $\varphi$ exceeds $0.05^{\circ}$, it gradually increases as the imposed torque $T$ increases. It is found that there is a certain nonlinearity until the torque $T$ reaches the set value of $3000 \mathrm{~N} \cdot \mathrm{m}$. In order to calculate the torsional stiffness $K_{T}$ at $3000 \mathrm{~N} \cdot \mathrm{m}$, two points $\left(0.141^{\circ}, 2397 \mathrm{~N} \cdot \mathrm{m}\right)$ and $\left(0.157^{\circ}\right.$, $3000 \mathrm{~N} \cdot \mathrm{m}$ ) are considered on the curve. Then the torsional stiffness can be calculated in Equation (2):

$$
K_{T}=\frac{180 \times \Delta T}{\Delta \varphi \times \pi}=\frac{180 \times(3000-2397)}{(0.157-0.141) \times \pi}=1.88 \times 10^{6} \mathrm{~N} \cdot \mathrm{m} / \mathrm{rad}
$$

Table 3 compares the torsional stiffness at $3000 \mathrm{~N} \cdot \mathrm{m}$ obtained from the simulation and the experiment and shows the relative error of simulation. It is observed that the calculated stiffness has excellent agreement with that of the experiment. This demonstrates the accuracy of the established model and settings of boundary conditions. 
Table 3. Torsional stiffness obtained from the numerical method and the experiment.

\begin{tabular}{cccc}
\hline Parameter Name & Test Result & Simulation Result & Relative Error \\
\hline Torsional stiffness $K_{T}(\mathrm{~N} \cdot \mathrm{m} / \mathrm{rad})$ & $1.88 \times 10^{6}$ & $1.79 \times 10^{6}$ & $4.8 \%$ \\
\hline
\end{tabular}

\section{Investigating the Influence of the Flange Elasticity on the Stiffness of the Laminated Membrane Coupling}

The main flexible components of laminated membrane couplings are laminated groups with multi-layer close fitting. It is worth noting that laminated groups are key components for transmitting the mechanical power and torque, compensating the displacement between the master and the slave, and compensating misalignments between the moving shafts. Scholars have performed many investigations on this issue. However, the majority of these investigations are focused on the stiffness of laminated groups and consider the flange as a rigid body. Studies show that the flange elasticity also affects the coupling stiffness. Therefore, it is intended to study the influence of the flange elasticity on the stiffness of the laminated membrane coupling through the comparative analysis of the coupling stiffness.

In order to investigate the flange impact on the overall stiffness of the coupling, the simulation in Section 2.2 is used to analyze the laminated membrane coupling and obtain the stiffness of the laminated membrane coupling. Then the influence of the flange deformation is not considered, and the simulation stiffness of the laminated group model is calculated separately. The elastic modulus of the flange plate is set to $2 \times 10^{15} \mathrm{~Pa}$, which means that the flange plate is considered as a rigid body and the deformation of flange plate is ignored. Then the calculation is carried out again until the stiffness of the lamination group is calculated.

\subsection{Torsional Stiffness Analysis of the Laminated Membrane Coupling and the Lamination Group}

In this section, the driven flange is fixed and a torque of $3000 \mathrm{~N} \cdot \mathrm{m}$ is applied on the active flange. Then the load sub-step method, which is divided into five sub-steps, is applied to analyze the torsional stiffness of the laminated membrane coupling and the lamination group.

The end face of the driven flange is set to fixed support, and two load steps are set for load application, as shown in Figure 13. On the sides of the six bolts, the 'bolt pre-tightening force of $15 \mathrm{kN}$ is set' in the first step, and 'lock is set' in the second step. Tabular data is used to load the end face of the active flange. The first step is set to 0 , the second step is to apply a torque of $3000 \mathrm{~N} \cdot \mathrm{m}$, and the second step is to set 5 sub-steps, and the loading torque is $600 \mathrm{~N} \cdot \mathrm{m}, 1200 \mathrm{~N} \cdot \mathrm{m}, 1800 \mathrm{~N} \cdot \mathrm{m}, 2400 \mathrm{~N} \cdot \mathrm{m}$ and $3000 \mathrm{~N} \cdot \mathrm{m}$ respectively.

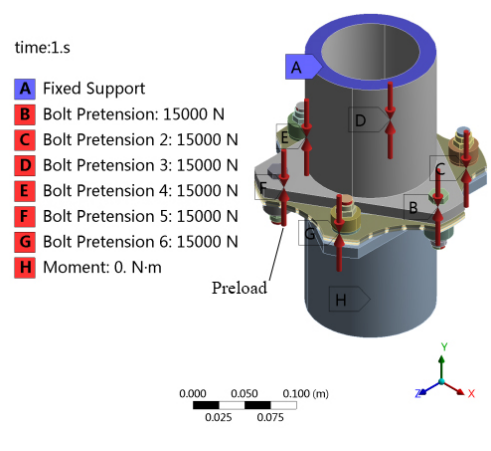

(a) First step

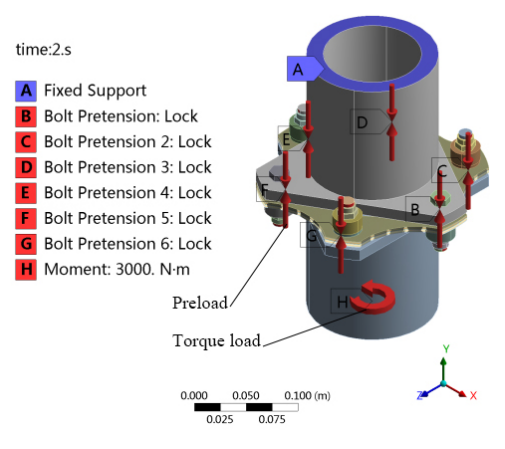

(b) Second step

Figure 13. Boundary condition settings for torsional stiffness simulation.

Through the simulation analysis, the corresponding rotational angular displacement of the laminated membrane coupling and the lamination group for torques of $600 \mathrm{~N} \cdot \mathrm{m}, 1200 \mathrm{~N} \cdot \mathrm{m}, 1800 \mathrm{~N} \cdot \mathrm{m}$, $2400 \mathrm{~N} \cdot \mathrm{m}$ and $3000 \mathrm{~N} \cdot \mathrm{m}$ can be obtained. Then the torsional stiffness can be calculated by Equation (1). 
Figure 14 shows the corresponding rotation angular displacement and torsional stiffness of the laminated membrane coupling and the coupling laminated group under different torque loads. It can be seen from the figure that the torque and rotational angular displacement of laminated membrane coupling has a certain nonlinear correlation within the range of $0-3000 \mathrm{~N} \cdot \mathrm{m}$, and the same is true for the coupling lamination group. For the laminated membrane coupling, the torsional stiffness is estimated to $1.8 \times 10^{6} \mathrm{~N} \cdot \mathrm{m} / \mathrm{rad}$. Furthermore, for the coupling lamination group, the torsional stiffness is approximately $5.45 \times 10^{6} \mathrm{~N} \cdot \mathrm{m} / \mathrm{rad}$. Since the stiffness value is large, it can be considered that the laminated membrane coupling is rigid along the torsional direction.

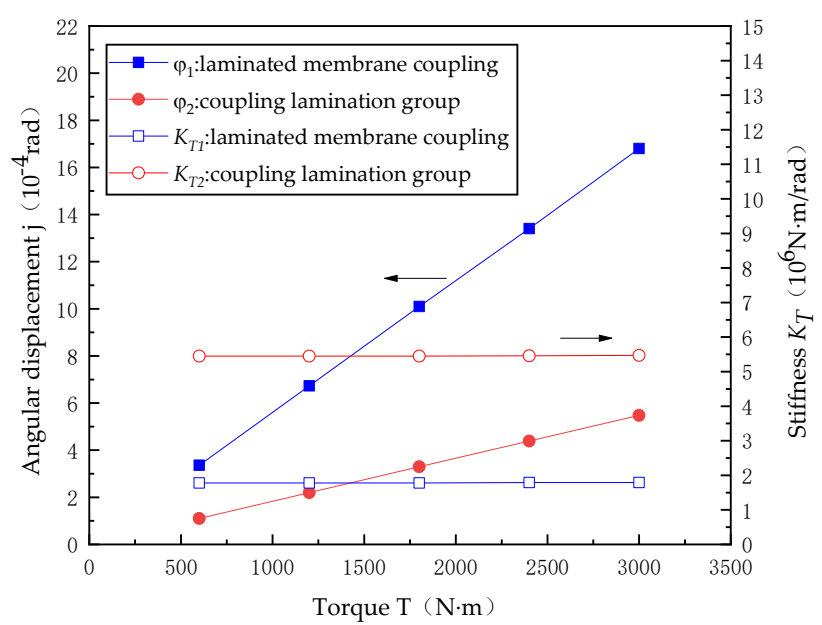

Figure 14. Influence of the flange elasticity on the angular displacement and torsional stiffness.

\subsection{Axial Stiffness Analysis of the Laminated Membrane Coupling and the Lamination Group}

In this section, the pre-tightening force of connecting bolts between the driving and driven flanges is set to $15,000 \mathrm{~N}$. After fixing the driven flange, an axial displacement of $1 \mathrm{~mm}$ is applied on the active flange. Then the load sub-step method, which is divided into 5 sub-steps, is applied to analyze the axial stiffness of the laminated membrane coupling and the lamination group.

The end face of the driven flange is set to "fixed support", and two load steps are set to apply the load, as shown in Figure 15. On the side of the six bolts, the preload of the first bolt is set to $15 \mathrm{kN}$. Then 'set the lock' is applied in the second step. Table data is then used to load the end face of the active flange. The first step is set to 0 , and the second step is set to $1 \mathrm{~mm}$ axial displacement. In the second step, five sub steps were set up, and the loading displacements were $0.2 \mathrm{~mm}, 0.4 \mathrm{~mm}, 0.6 \mathrm{~mm}$, $0.8 \mathrm{~mm}$ and $1 \mathrm{~mm}$, respectively.

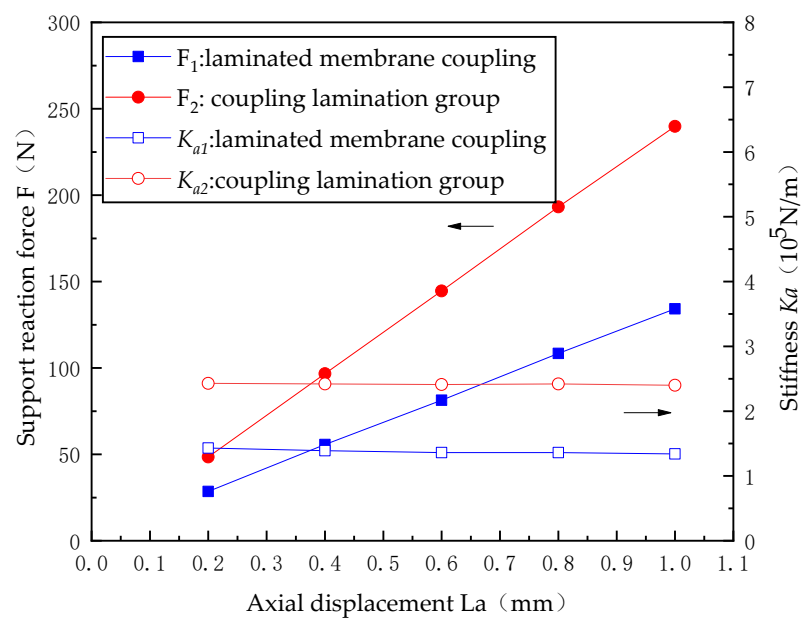

Figure 15. Influence of the flange elasticity on the reaction force and axial stiffness. 
Through the simulation analysis, the corresponding reaction forces of the laminated membrane coupling and the lamination group for axial displacements of $0.2 \mathrm{~mm}, 0.4 \mathrm{~mm}, 0.6 \mathrm{~mm}, 0.8 \mathrm{~mm}$ and $1 \mathrm{~mm}$ are obtained. In this case, the axial stiffness $K_{a}$ of the laminated membrane coupling and the lamination group can be expressed as:

$$
K_{a}=\frac{\mathrm{d} F}{\mathrm{~d} L_{a}} \approx \frac{\Delta F}{\Delta L_{a}}
$$

Figure 15 shows the corresponding reaction force and axial stiffness of the laminated membrane coupling and the coupling lamination group are loaded under different axial displacements loads. It can be seen from the figure that for a small displacement range (i.e., axial displacement $0-1 \mathrm{~mm}$ ), there is a nonlinear correlation between the axial force and displacement of the laminated membrane coupling, and the same is true for the coupling lamination group. In this range, the axial stiffness of the laminated membrane coupling is approximately $1.4 \times 10^{5} \mathrm{~N} / \mathrm{m}$. Meanwhile, it is found that the axial stiffness of the coupling lamination group is approximately $2.40 \times 10^{5} \mathrm{~N} / \mathrm{m}$. It should be indicated that this stiffness value is relatively small so that the laminated membrane coupling can be considered as a flexible component along the axial direction.

\subsection{Radial Stiffness Analysis of the Laminated Membrane Coupling and the Lamination Group}

In this section, the pre-tightening force of connecting bolts between the driving and driven flanges are set to $15,000 \mathrm{~N}$. After fixing the driven flange, a radial displacement of $0.5 \mathrm{~mm}$ is applied on the active flange. Then the sub-step method, which is divided into five sub-steps, is applied to analyze the radial stiffness of the laminated membrane coupling and the lamination group.

In the software, the cylindrical surfaces of the three bolts connected with the driven flange are set as fixed support constraints, the loading process is divided into two load steps, the first step is to set the bolt preload of $15 \mathrm{kN}$, and the second step is to set the lock. The cylindrical surfaces of the three bolts connected with the active flange are subjected to a displacement load in the $\mathrm{X}$ direction, and use tabular data to load, the first step is set to 0 , the second step is set to $5 \mathrm{~mm}$ displacement load, and five sub-steps are set, the loads of the five sub-steps are $0.1 \mathrm{~mm}, 0.2 \mathrm{~mm}, 0.3 \mathrm{~mm}, 0.4 \mathrm{~mm}$ and $0.5 \mathrm{~mm}$ respectively.

From the structure of the laminated membrane coupling, it can be seen that the effect of the radial displacement in the $\mathrm{X}$ and $\mathrm{Z}$ direction on the coupling is different, so the same displacement constraint is also applied in the Z- direction for analysis.

Through the simulation analysis, the corresponding reaction force of laminated membrane coupling and the lamination group for the radial displacement of $0.1 \mathrm{~mm}, 0.2 \mathrm{~mm}, 0.3 \mathrm{~mm}, 0.4 \mathrm{~mm}$ and $0.5 \mathrm{~mm}$ are obtained. Then the radial stiffness $K_{r}$ of the laminated membrane coupling and the lamination group can be calculated as the following:

$$
K_{r}=\frac{\mathrm{d} F}{\mathrm{~d} L} \approx \frac{\Delta F}{\Delta L}
$$

Figure 16 shows the reaction force and the corresponding stiffness of the radial displacement along the X-and Z- directions of the laminated membrane coupling and the coupling lamination group in each load sub-step.

Figure 16 demonstrates that for small displacements (i.e., radial displacements within the range of $0-0.5 \mathrm{~mm}$ ), there is a nonlinear correlation between the radial force and displacement of the laminated membrane coupling along $X$ - and Z-directions. The same is true for the coupling lamination group. Moreover, it is observed that the radial stiffness along the $X$-direction is slightly less than that along the Z-direction. In other words, for the laminated membrane coupling, the radial stiffness along the $\mathrm{X}$-direction is about $8.92 \times 10^{8} \mathrm{~N} / \mathrm{m}$, while the radial stiffness along the Z-direction is about $8.98 \times 10^{8} \mathrm{~N} / \mathrm{m}$. For the coupling lamination group, the stiffness along the $X$-direction varies within the range of $9.14 \times 10^{8}-9.26 \times 10^{8} \mathrm{~N} / \mathrm{m}$, while that along the Z-direction varies within the range of 
$9.16 \times 10^{8}-9.26 \times 10^{8} \mathrm{~N} / \mathrm{m}$. In a word, both stiffness values are large so that the laminated membrane coupling along the radial direction can be considered as a rigid component.

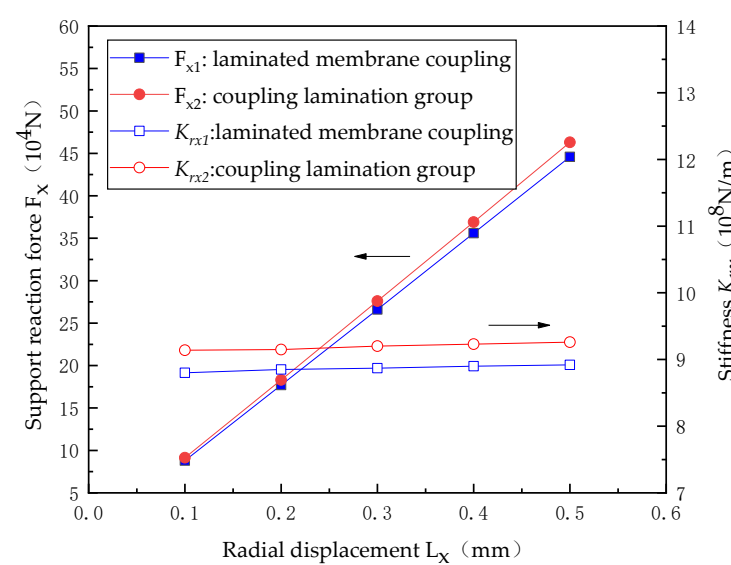

(a) In the X-direction

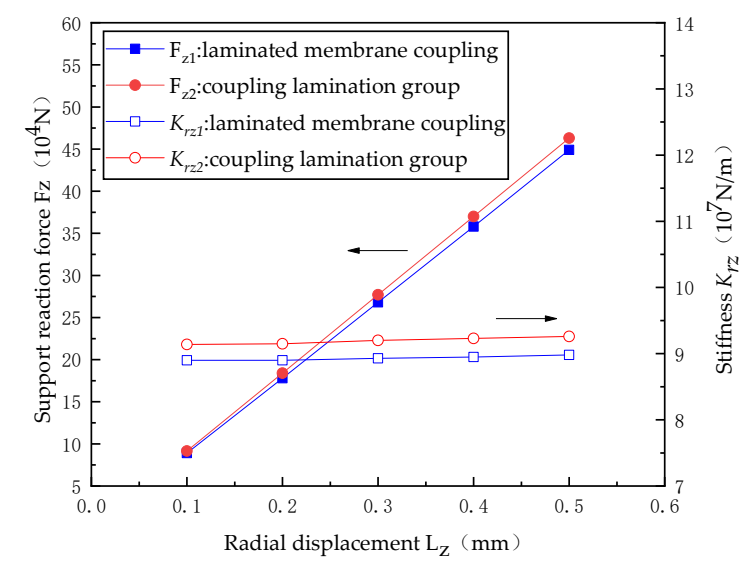

(b) In the Z-direction

Figure 16. Influence of the flange elasticity on the reaction force and radial stiffness along $X$ and Z-directions.

\subsection{Angular Stiffness Analysis of the Laminated Membrane Coupling and the Lamination Group}

In this analysis, the pre-tightening force of connecting bolts between driving and driven flanges are set to $15 \mathrm{kN}$. After fixing the driven flange, a rotational angle of $0.5^{\circ}$ is applied on the active flange. Then the load sub-step method, which is divided into five sub-steps, is applied to analyze the angular stiffness of the laminated membrane coupling and the lamination group.

In the software, the end face of the driven flange is set as a fixed support constraint. The loading process is divided into two load steps, load on the sides of six bolts, set a pre-tightening force of $15 \mathrm{Kn}$ in the first step, and lock in the second. An angular displacement load in the $\mathrm{X}$ direction is applied to the end face of the active flange. Through the tabular data tool, the first step is set to $0^{\circ}$, the second step is set to $0.5^{\circ}$, the second load step is divided into five sub-steps, the values are $0.1^{\circ}, 0.2^{\circ}, 0.3^{\circ}, 0.4^{\circ}$ and $0.5^{\circ}$ respectively.

It can be seen from the structure of the laminated group that the effect of the angular displacement in the $\mathrm{X}$ and $\mathrm{Z}$ direction on the coupling is different, so the same angular displacement in the $\mathrm{Z}$ direction is also applied for analysis.

Through the simulation analysis, the reaction moment of the laminated membrane coupling and the lamination group at the rotational angles of $0.1^{\circ}, 0.2^{\circ}, 0.3^{\circ}, 0.4^{\circ}$ and $0.5^{\circ} \mathrm{can}$ be obtained. In this case, the angular stiffness $K_{\alpha}$ of the laminated membrane coupling and the lamination group can be expressed as:

$$
K_{\alpha}=\frac{\mathrm{d} M}{d \theta \times \pi / 180} \approx \frac{180 \Delta M}{\pi \Delta \theta}
$$

Figure 17 shows the reaction moment and the corresponding stiffness of different rotational angles along the $\mathrm{X}$ and $\mathrm{Z}$ directions of the laminated membrane coupling and the coupling lamination group in each load sub-step.

Figure 17 indicates that for a small displacement range (i.e., rotational angles within the range of $0-0.5^{\circ}$ ), there is a nonlinear correlation between the bending moment and displacement of the laminated membrane coupling along the X- and Z-directions. The same is true for the coupling lamination group. Moreover, it is found that the angular stiffness along the $X$-direction is slightly greater than that along the Z-direction. In other words, for the laminated membrane coupling, the angular stiffness along the X-direction is about $4.50 \times 10^{3} \mathrm{~N} \cdot \mathrm{m} / \mathrm{rad}$, while that along the Z-direction is about $4.48 \times 10^{3} \mathrm{~N} \cdot \mathrm{m} / \mathrm{rad}$. For the coupling lamination group, the stiffness along the $X$-direction 
varies within the range of $6.11 \times 10^{3}-6.21 \times 10^{3} \mathrm{~N} \cdot \mathrm{m} / \mathrm{rad}$, while that along the Z-direction varies within the range of $6.03 \times 10^{3}-6.18 \times 10^{3} \mathrm{~N} \cdot \mathrm{m} / \mathrm{rad}$. Anyway, both stiffness values are relatively small so that the laminated membrane coupling along the circumferential direction can be assumed as flexible.

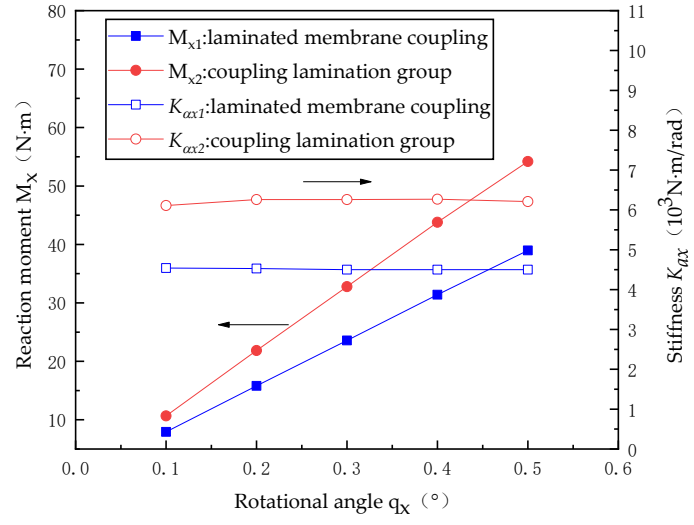

(a) In the X-direction

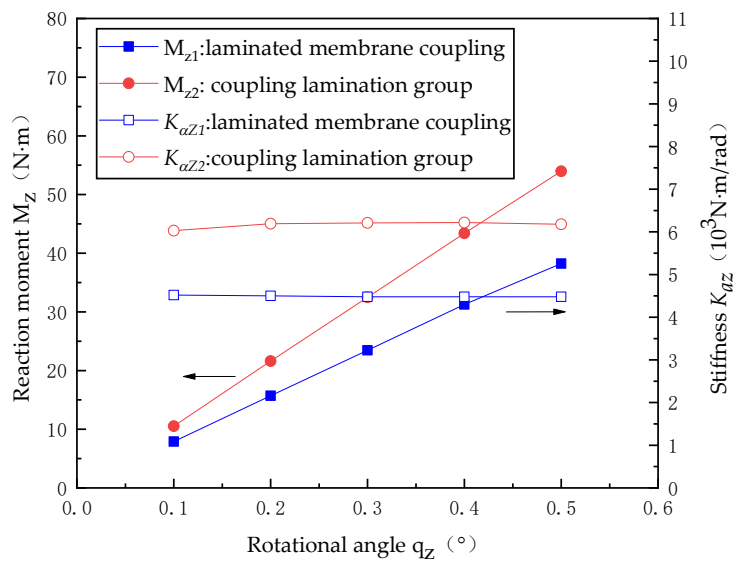

(b) In the Z-direction

Figure 17. Influence of the flange elasticity on the reaction moment and angular stiffness along $X-$ and Z-directions.

\subsection{The Influence of the Flange Elasticity on Different Stiffness of the Laminated Membrane Coupling}

In the foregoing sections, the finite element simulation is performed to obtain the torsional, radial, axial and angular stiffness of the coupling and lamination group. Table 4 shows the obtained results in this regard. It indicates that the order of magnitude of torsional and radial stiffness is far greater than that of the axial and angular stiffness, indicating that the laminated membrane coupling is rigid in torsion and radial directions. Subsequently, it can mainly provide compensation for axial and angular displacements. Moreover, it is found that all stiffness values of the whole coupling are smaller than the corresponding stiffness of the lamination group, which is in line with the actual situation. This can be interpreted as the following: existence of the flange is equivalent to the series connection with the lamination group along the torsional, axial, radial and angular directions. On the other hand, series connection reduces the total stiffness of the system. In other words, the flange imposes the biggest reduction in the overall torsional stiffness of the coupling. This reduction can be up to 0.33 laminated group stiffness. Meanwhile, axial, angular and radial stiffness of the flange can reduce the overall torsional stiffness of the coupling up to $0.58,0.73$ and 0.97 laminated group radial stiffness, respectively. Therefore, the flange influence on the stiffness of the coupling is in order of torsional, axial, angular and radial stiffness.

Table 4. Obtained stiffness values of the coupling and lamination group from the simulation and the experiment.

\begin{tabular}{cccc}
\hline Stiffness Category & Laminated Membrane Coupling & Lamination Group & $\begin{array}{c}\text { Laminated Membrane } \\
\text { Coupling/ Lamination Group }\end{array}$ \\
\hline Torsional stiffness $K_{T}(\mathrm{~N} \cdot \mathrm{m} / \mathrm{rad})$ & $1.80 \times 10^{6}$ & $5.45 \times 10^{6}$ & 0.33 \\
Axial stiffness $K_{a}(\mathrm{~N} / \mathrm{m})$ & $1.40 \times 10^{5}$ & $2.40 \times 10^{5}$ & 0.58 \\
Radial stiffness $K_{r}(\mathrm{~N} / \mathrm{m})$ & $8.90 \times 10^{8}$ & $9.20 \times 10^{8}$ & 0.97 \\
Angular stiffness $K_{\alpha}(\mathrm{N} \cdot \mathrm{m} / \mathrm{rad})$ & $4.50 \times 10^{3}$ & $6.20 \times 10^{3}$ & 0.73 \\
\hline
\end{tabular}

\section{Analyzing the Friction Impact on the Stiffness of the Laminated Membrane Coupling}

The friction force is affected by pre-tightening force and friction coefficient. In this section, it is intended to analyze the influence of bolt pre-tightening force and friction coefficient on the stiffness of 
the laminated membrane coupling to investigate the influence of the friction force on the torsional, axial, radial and angular stiffness of the laminated membrane coupling.

\subsection{Analyzing the Influence of the Bolt Preload on the Stiffness of the Laminated Membrane Coupling}

In this section, the influence of the bolt preload on the stiffness of laminated membrane coupling with constant coupling dimensions is studied. In order to facilitate the comparison, only stiffness values obtained from the last sub-step of the second load step is taken for the analysis. The torque, axial displacement, radial displacement, and the rotational angle is set to $3000 \mathrm{~N} \cdot \mathrm{m}, 1 \mathrm{~mm}, 0.5 \mathrm{~mm}$ and $0.5^{\circ}$. It should be indicated that since the radial and angular stiffness along $X$ - and Z-directions have negligible differences, they are analyzed along the $\mathrm{X}$-direction.

For the foregoing loads, the bolt preload is set to $5 \mathrm{kN}, 10 \mathrm{kN}, 15 \mathrm{kN}$ and $20 \mathrm{kN}$, respectively, and the other boundary conditions are remained unchanged.

Moreover, friction coefficient is set to $0.1,0.2$ and 0.3 , respectively, to investigate the influence of the bolt preload on various stiffness settings.

Figures 18-21 show that when the friction coefficient is set to $0.1,0.2$ and 0.3 , increasing the bolt preload will increase torsional, axial, radial and angular stiffness of the laminated membrane coupling. Furthermore, when the preload increases from $5 \mathrm{kN}$ to $20 \mathrm{kN}$, the variation of torsional, axial, radial, and angular stiffness are $1.6 \%, 66 \%, 1.1 \%$ and $5.2 \%$, respectively. It is found that the bolt preload has the greatest impact on the axial stiffness, which is far greater than other stiffness.

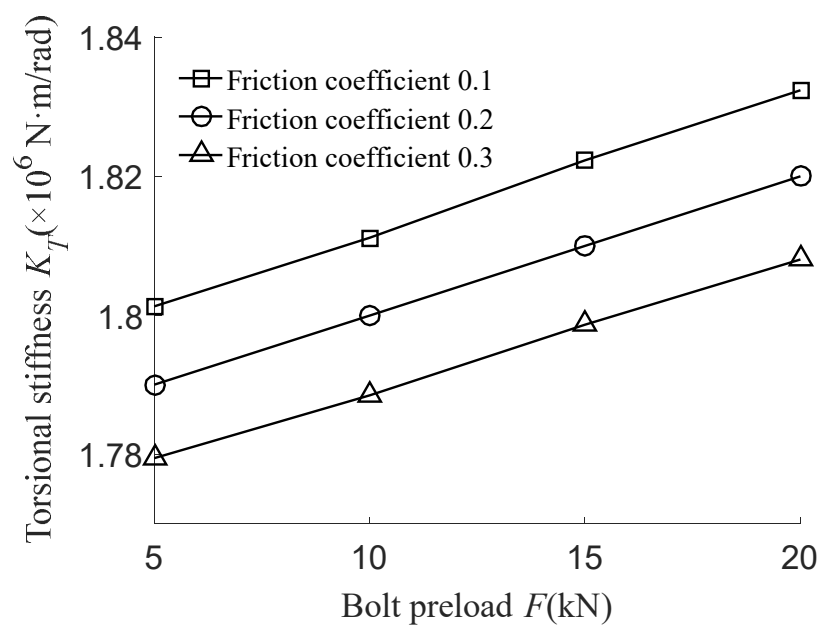

Figure 18. Influence of the bolt preload on the torsional stiffness.

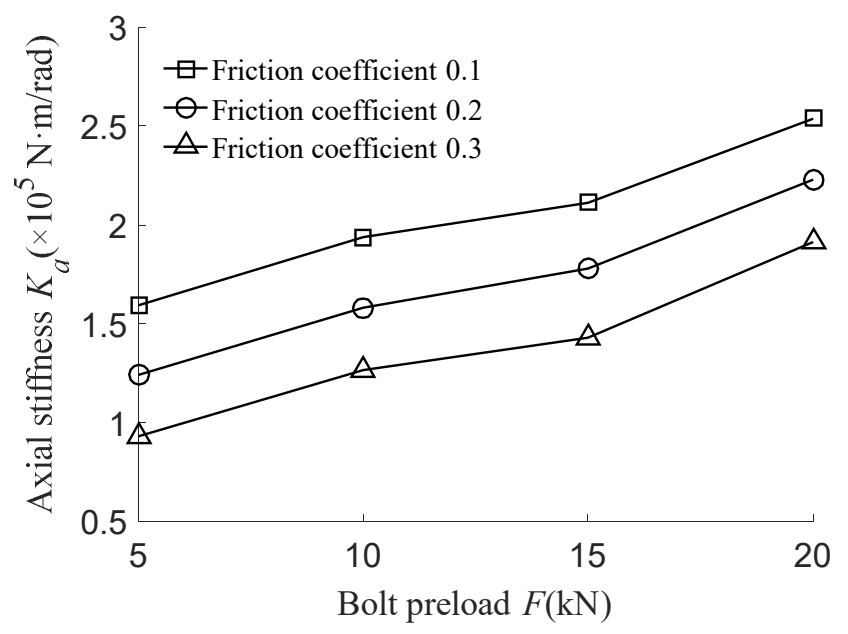

Figure 19. Influence of the bolt preload on the axial stiffness. 


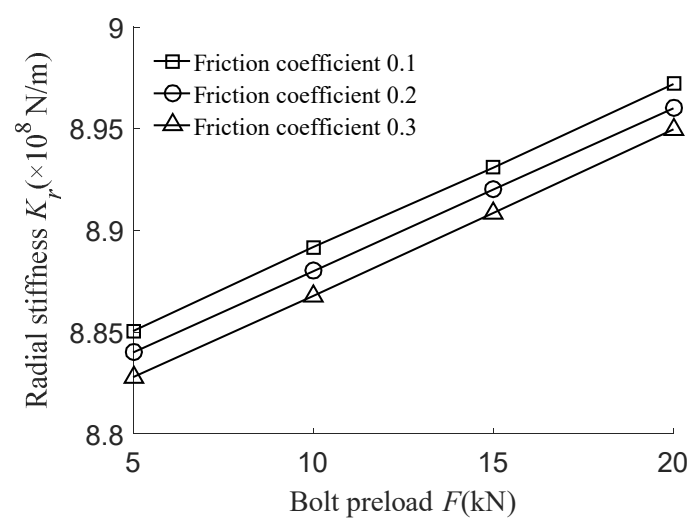

Figure 20. Influence of the bolt preload on the radial stiffness.

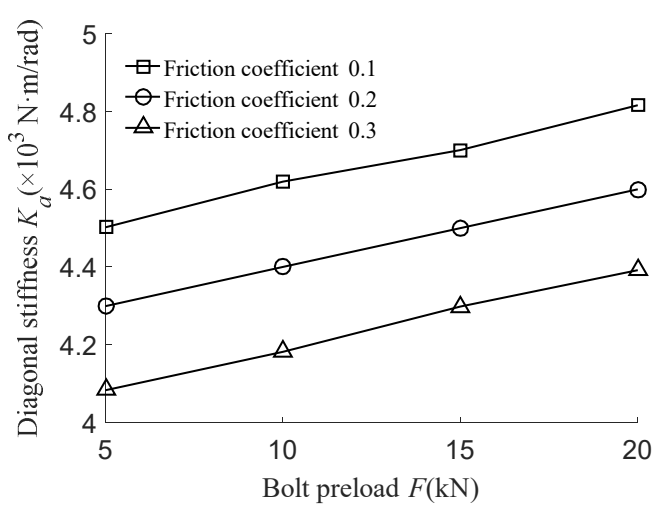

Figure 21. Influence of the bolt preload on the diagonal stiffness.

\subsection{Analyzing the Influence of Friction Coefficient on the Stiffness of the Laminated Membrane Coupling}

The influence of friction coefficient between laminations with constant coupling dimensions on the coupling stiffness is studied. For above mentioned various loads, the friction coefficient between the laminations is set to $0.1,0.15,0.2,0.25,0.3,0.35$ and 0.4 respectively, while other boundary conditions are remained unchanged to study the influence of friction coefficient on various stiffness of the coupling.

Moreover, the bolt preload is set to $10 \mathrm{kN}, 15 \mathrm{kN}$ and $20 \mathrm{KN}$ to get the influence of friction coefficient value on various stiffness settings with different bolt preloads.

Figures 22-25 show that when the bolt preload is $10 \mathrm{kN}, 15 \mathrm{kN}$ and $20 \mathrm{kN}$, increasing the friction coefficient will reduce the torsional, axial, radial and angular of the laminated membrane coupling. More specifically, when friction coefficient increases from 0.1 to 0.4 , variations of torsional, axial, radial and angular are $4.4 \%, 46 \%, 0.6 \%$ and $1.1 \%$, respectively.

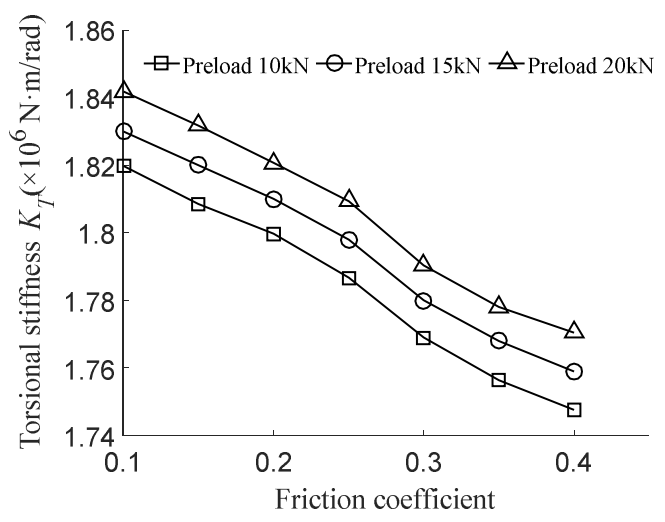

Figure 22. Influence of the friction coefficient on the torsional stiffness. 


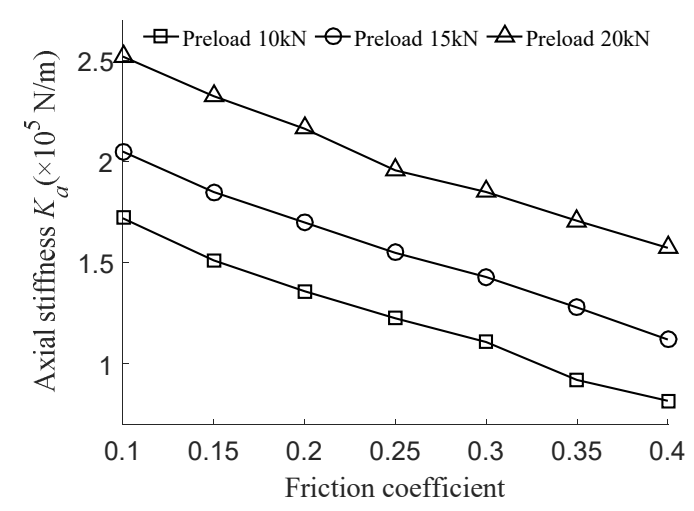

Figure 23. Influence of the friction coefficient on the axial stiffness.

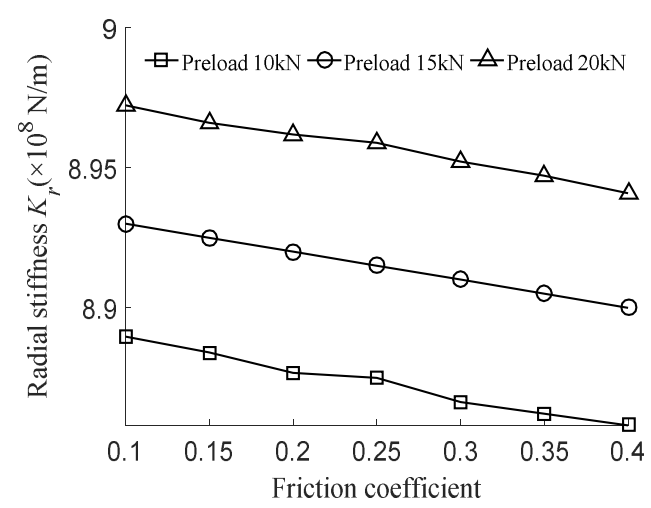

Figure 24. Influence of the friction coefficient on the radial stiffness.

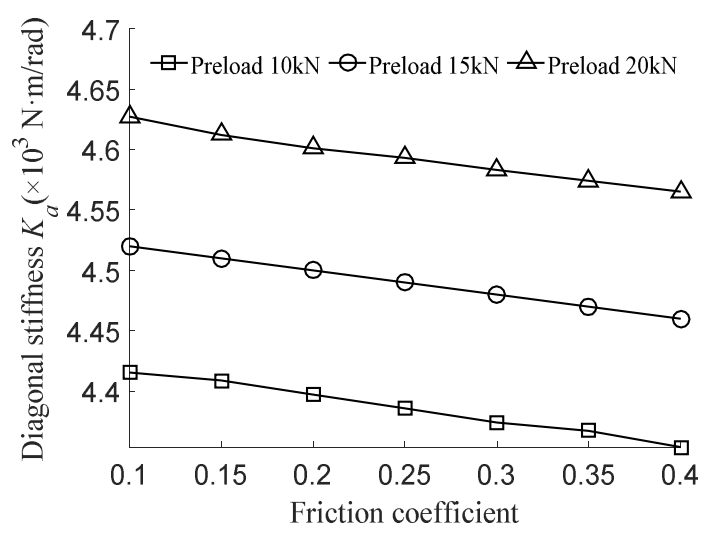

Figure 25. Influence of the friction coefficient on the diagonal stiffness.

\section{Conclusions}

In the present study, four types of laminated membrane coupling stiffness are studied through the finite element method. To this end, torsion, axial, radial and angular stiffness are studied. Moreover, the torsional stiffness is verified through the static torsional test, and the influence of flange elasticity and friction coefficient between laminated plates on the stiffness characteristics of coupling is studied. Based on the results, the authors concluded that:

1. The finite element model of the laminated membrane coupling with multi-layer laminated contact is established, and its torsional stiffness is analyzed. Based on the electro-hydraulic servo shaft torsional fatigue testing machine, the static torsional test of the laminated membrane coupling is carried out. Obtained results from the numerical simulation are in excellent agreement with those from the experiment. Therefore, the accuracy of finite element simulation is approved. 
2. Based on the finite element simulation, torsional, axial, radial and angular stiffness of the laminated membrane coupling and laminated group are analyzed. Obtained results show that the order of magnitude of torsional and radial stiffness is far greater than that of axial and angular stiffness. It indicates that laminated membrane couplings are rigid in torsional and radial directions so that only axial and angular displacements are compensated. Moreover, it is found that all stiffness values of couplings are smaller than that of laminated groups. Because, the existence of the flange is equivalent to that of laminated groups in all directions with series connection. The influence degree of the flange on all the stiffness of coupling is in order of torsional, axial, angular and radial stiffness.

3. Through the finite element simulation, the influence of the bolt preload and friction coefficient between the laminations on the four types of coupling stiffness is studied. Obtained results show that increasing the preload will increase the torsion, axial, radial and angular stiffness, while increasing the friction coefficient will reduce the torsion, axial, radial and angular stiffness. It is found that variation of both factors has the greatest impact on the axial stiffness.

Author Contributions: Conceptualization, M.L. and Y.Z.; methodology, M.L.; validation, P.L. and R.Z.; writing—original draft preparation, M.L.; writing—review and editing, Y.Z.; All authors have read and agreed to the published version of the manuscript.

Funding: This research is supported by the National Natural Science Foundation of China (Grant No. 51775265), and the National Key Laboratory of Science and Technology on Helicopter Transmission (Nanjing University of Aeronautics and Astronautics) (Grant No. HTL-A-19G09).

Conflicts of Interest: The authors declare no conflict of interest.

\section{References}

1. Jiashou, H. New Coupling and Clutch; Shanghai Science and Technology Press: Shanghai, China, 1989.

2. Guoqing, Y.; Yuedong, W. Performance analysis of diaphragm coupling. Fan Technol. 2010, 2, 19-22+36.

3. Shuang, L. Topological Design and Dynamic Analysis of Flexible Laminated Membrane Coupling Based on ANSYS. Master's Thesis, Nanjing University of Aeronautics and Astronautics, Nanjing, China, 2004.

4. Kim, K.; Ludema, K.C. A Correlation between low cycle fatigue properties and scuffing properties of 4340 steel. J. Tribol. 1995, 117, 617-621. [CrossRef]

5. Shentu, L.F.; Hongtao, T.; Chengxuan, W. Strength analysis of chain laminated membrane coupling. Mech. Sci. Technol. 1998, 17, 3-5.

6. Shentu, L.F.; Yang, P. The study on the torque carrying capacity of the joint bearing six-hole style laminated membrane coupling. Appl. Mech. Mater. 2011, 101, 597-600. [CrossRef]

7. Caliciotti, A.; Fasano, G.; Nash, S.G.; Massimo, R. An adaptive truncation criterion, for linesearch-based truncated Newton methods in large scale nonconvex optimization. Oper. Res. Lett. 2018, 46, 7-12. [CrossRef]

8. Caliciotti, A.; Fasano, G.; Nash, S.G.; Massimo, R. Data and performance profiles applying an adaptive truncation criterion, within linesearch-based truncated Newton methods, in large scale nonconvex optimization. Data Brief 2018, 17, 246-255. [CrossRef] [PubMed]

9. Duong, L.; Kazerounian, K. Design improvement of the mechanical coupling diaphragms for aerospace applications. Mech. Based Des. Struct. Mach. 2007, 35, 467-479. [CrossRef]

10. Khosravi, P. Nonlinear Finite Element Analysis and Design Optimization of Thin-Walled Structures. Ph.D. Thesis, Concordia University, Montreal, QC, Canada, 2007.

11. Khosravi, P.; Ganesan, R.; Sedaghati, R. An efficient facet shell element for corotational nonlinear analysis of thin and moderately thick laminated composite structures. Comput. Struct. 2008, 86, 850-858. [CrossRef]

12. Khosravi, P.; Ganesan, R.; Sedaghati, R. Limit load analysis of thin geometrically nonlinear structures using a new shell element. In Proceedings of the 47th AIAA/ASME/ASCE/AHS/ASC Structures, Structural Dynamics, and Materials Conference 14th AIAA/ASME/AHS Adaptive Structures Conference 7th, Newport, RI, USA, 4 May 2006; p. 2276.

13. Cheng, M. Nonlinear Finite Element Analysis of Laminated Membrane Couplings; Nanjing University of Aeronautics and Astronautics: Nanjing, China, 2006. 
14. Dongsheng, W.; Xiaoxin, X.; Kai, Z. Research on calculation of torsional stiffness of high power diaphragm coupling. Mech. Transm. 2006, 30,7-8+96.

15. Liufang, S.; Xiangyan, Z. The study about designing the structure of the joint flexible laminated membrane coupling (JFLMC). In Proceedings of the 2010 Third International Conference on Information and Computing, Wuxi, China, 4 June 2010; pp. 109-112.

16. Guanglin, D.; Yunbin, Z.; Duo, S.; Lifeng, X. Effect of contact state on the strength and stiffness of diaphragm components. Ship Sci. Technol. 2010, 8, 157-161.

17. Wei, W. Strength Life Analysis and Dynamic Characteristics Analysis of Laminated Membrane Couplings. Master's Thesis, Nanjing University of Aeronautics and Astronautics, Nanjing, China, 2013.

18. Liufang, S.T.; Chenglong, S.; Zunguo, G. Study on the angular stiffness of laminated membrane couplings. Mech. Eng. 2013, 24, 1897-1901.

19. Liufang, S.T.; Chenglong, S. Calculation of lamination stiffness of joint laminated membrane couplings. Mech. Strength 2013, 35, 531-536.

20. Junfeng, N. Research on the Structure and Dynamic Characteristics of Helicopter Drive Shaft System. Ph.D. Thesis, Harbin University of Science and Technology, Harbin, China, 2016.

21. Jingming, L.; Bing, Y. Analysis of the effect of diaphragm coupling structure on its torsional stiffness. Mech. Eng. Autom. 2016, 1, 81-82+85.

22. Youtao, L.; Zhihe, Z.; Bing, Y.; Guangwu, Y.; Shoune, X.; Tao, Z. Research on the nonlinear characteristics of laminated membrane coupling under different load forms. Mech. Transm. 2019, 43, 34-39.

Publisher's Note: MDPI stays neutral with regard to jurisdictional claims in published maps and institutional affiliations.

(C) 2020 by the authors. Licensee MDPI, Basel, Switzerland. This article is an open access article distributed under the terms and conditions of the Creative Commons Attribution (CC BY) license (http://creativecommons.org/licenses/by/4.0/). 